\title{
Awareness of adverse health effects of silica dust exposure among stone quarry workers in Ghana
}

\author{
Dzifa Francis Ahadzi* \\ Center for Occupational Safety and Health \\ Health and Safety Group Africa (HESAG Africa) \\ Cape Coast, Ghana
}

Email: dzifa.hesag@gmail.com

*Author to whom correspondence should be addressed

Declaration of interest: None

\begin{abstract}
Background: Work experience is a key factor that influences safety awareness among workers. This study investigated the influence of work experience on the level of awareness on adverse health effects of silica dust exposure among stone quarry workers in Ghana while controlling for theoretically relevant compositional and contextual factors, evaluated the magnitude and order of association between the predictors and the predicted variable. Method: A cross-sectional survey data of 524 randomly selected stone quarry workers were subjected to multivariate statistical analyses. Results: Stone quarry workers who had 6 to10 years and more than 10 years of work experience were $48 \%(\mathrm{OR}=1.475, \mathrm{P}=0.021)$ and $82 \%$ $(\mathrm{OR}=1.816, \mathrm{P}=0.003)$ respectively more likely to be aware of the adverse health effects of silica dust exposure compared to their counterparts who had 1 to 5 years work experience. Conclusion: These findings provide relevant information for managers and policymakers to plan and maximize awareness on silica dust health hazards among silica exposed workers.
\end{abstract}

Keywords: awareness, adverse health effects, exposure, stone quarry workers, silica dust 


\section{Introduction}

Occupational exposure to crystalline silica dust poses serious health threats to stone quarry workers particularly in developing countries (Ahadzi et al., 2020; Kabir et al., 2018; Rees et al., 2009) Stone quarry workers in developing countries are exposed to health hazards associated with silica dust due to the unsafe working conditions that are present in these parts of the world. Crystalline silica dust has long been confirmed to have adverse health effects on silica-exposed workers (Maciejewska, 2008; Rees et al., 2009; Yassin Abdiaziz et al., 2005). Research has revealed that exposure to silica dust can lead to diseases such as silicosis, pulmonary fibrosis (Castranova V \& Vallyathan V, 2000; Dahmann et al., 2008; Ding et al., 2002), and lung cancer (Attfield \& Costello, 2004; Rice et al., 2001). Unfortunately, a lot of silica-exposed workers especially in developing countries are usually unaware of the human health problems silica dust exposure could cause (Kabir et al., 2018). Awareness is having knowledge or understanding that a particular situation or fact exists. Sayler et al., (2018) posited that awareness of the harmful effects of silica dust exposure is critical for protecting workers' health. Raising awareness of the negative health effects of silica dust exposure can minimize the human health hazards on workers (Gottesfeld et al., 2019; Kabir et al., 2018). Workers' health and safety awareness can have an impact on their health and safety attitude at the workplace (Momani et al., 2017; Tam \& Fung, 2008).

One of the effective ways management can create awareness of the health hazards associated with silica dust exposure is through information materials for employees (Rees et al., 2009; Sharma et al., 2016). Unfortunately, limited research has been conducted on silica dust health hazard awareness in developing countries unlike in the developed world (Falk et al., 2019; Nandi et al., 2018; Sayler et al., 2018; Seaton et al., 1991; Sivanmani \& Rajathinakar, 2013). It is important silica exposed workers have adequate knowledge about the health hazards silica dust exposure can cause. Occupational safety and health awareness play a critical role in preventing accidents, injuries, and diseases at the workplace (Lugah et al., 2010). Awareness of the adverse health effects ensures that workers appreciate the consequences of inhaling silica dust and the protective measures they can take to prevent it (Kamkuimo et al., 2020).

Aluko et al., (2016) found that occupational hazard knowledge is associated with educational status. Studies have established a positive relationship between work experience, educational attainment, and workers' awareness of the adverse health effects of silica dust exposure. Studies have revealed that stone quarry workers who have higher work experience and higher education have a better understanding and knowledge of the health hazards associated with silica dust exposure than their counterparts who have lower educational attainment and work experience (Nguyen et al., 2021; Tadesse et al., 2016). Safety knowledge gained through work experience and hazard exposure can improve workers' health hazard awareness (Hasanzadeh et al., 2017). 
It is well documented that young workers have lower awareness on issues about their health and safety than their older counterparts (Dragano et al., 2018; Rohlman et al., 2013; Sabitu et al., 2009). Lower awareness on occupational risks like silica dust exposure among young employees is partly due to limited knowledge and work experience (Riley, 2012; Rohlman et al., 2013). A contradictory finding was made in this study where younger workers were more likely to be aware of the adverse health effects of silica dust exposure than their older colleagues.

There is a dearth of literature on the awareness of the adverse health effects of silica dust exposure among stone quarry workers in developing countries. In this study, I examined the impact of work experience on the level of awareness on adverse health effects of silica dust exposure among stone quarry workers in Ghana while controlling for theoretically relevant compositional and contextual factors, evaluated the magnitude and order of association between the predictors and the response variable.

\section{Materials and Methods}

\section{Study area}

The study was performed in the southern part of Ghana because majority of the country's stone quarries are located in the south (Ahadzi et al., 2020). The selected five southern regions are Central, Western, Greater Accra, Eastern, and Ashanti. Except Greater Accra region where six stone quarries were selected for data collected from the same community (Shai Hills), the team selected three communities in each region with each community having two stone quarries. Central (Yeresunkwa, Ojobi, Opeikuma), Western (Sekondi, Shama, Beposo), Eastern (Nsawam, Klo-Begoro, Yilo Krobo), and Ashanti (Barekese, Mpobi, Afrancho Buoho). The locations of the study communities are presented in Figure 1.

\section{Data collection}

This study is an aspect of a research project that investigated the human health risks associated with occupational exposure to silica dust in stone quarries in Ghana. Data were collected from thirty stone quarries in five southern regions (Central, Western, Greater Accra, Eastern, and Ashanti) between May 2018 to February 2019. Simple random sampling method was used to recruit the participants (eighteen years or above) for the study. Workers were assigned numbers in each of the thirty stone quarry sites that were visited, a random number generator was used to select twenty workers for data collection from each of the thirty quarry sites. In all, six hundred questionnaires were administered to twenty workers in each quarry site. Though all the participants agreed to take part in the study, seventy-six of them did not return 
their questionnaires. A total of five hundred and twenty-four completed questionnaires were retrieved and used for the study.

\section{Measures}

\section{Measured variable}

The predicted variable considered in this study is awareness of the adverse health effects of silica dust exposure among stone quarry workers. Participants were asked to answer yes or no to the question "are you aware that exposure to silica dust can be harmful to your health?". The binary response to the categorical variable was coded 0 (for no) and 1 (for yes).

\section{Main explanatory variable}

The selection of the key explanatory variable was based on literature, parsimony, and theoretical relevance. Work experience plays a key role in determining safety and health knowledge of workers, this why work experience was considered as the key predictor in this study.

\section{Compositional and contextual factors}

In this study, I controlled for compositional and contextual factors. Compositional factors are a combination of biosocial and socio-cultural factors. While biosocial factors include age, sex, race, and ethnicity, sociocultural factors include education, family status, marital status (Collins et al., 2017; Pol \& Thomas, 2013). Location-specific opportunities in a region or place or broader neighborhood attributes (Collins et al., 2017; Ross \& Mirowsky, 2008). The compositional factors considered in this study are age (young adult: less than 35 years, middle-aged adult: 35-55 years), education (no formal or primary, secondary or higher), family status (head, member), marital status (single, married, divorced). The contextual factor included in the study was the region of residence (Central, Western, Greater Accra, Eastern, and Ashanti).

\section{Data analyses}

Univariate and multivariate analyses were conducted on the data to determine the relationships and proportions between factors that influenced awareness on adverse health effects of silica dust exposure 
among stone quarry workers while controlling for relevant compositional and contextual factors. All statistical analyses were run using Stata 14 (StataCorp, College Station, TX, USA) SE software.

\section{Univariate analyses}

Pearson's chi-square test was used to examine the relationship between the measured variable (awareness of adverse health effects of silica dust exposure) and the main explanatory variable (work experience) as well as the compositional and contextual factors. Cramer's V statistic was employed to determine the strength of between the response variable and the predictor variables. When the Cramer's V statistic is equal or greater than 0.3 , the association is considered to be strong, however when it is less than 0.3 , the association is considered weak.

\section{Multivariate regression}

Complementary log-log regression was used to model the relationship between work experience and awareness of the harmful effects of silica dust exposure among stone quarry workers. Under the assumption of dichotomous response (no $=0$, yes $=1$ ), there are a couple of model options that can be used for this type of data depending on the link function of the generalized linear model (GLM): logit model, probit model, negative log-log model, and complementary log-log model. While logit and probit models are symmetrical, the complementary log-log model is asymmetrical. The link function for this model is apt for binary outcomes that are asymmetrical. The complementary log-log model is employed when the probability of an event is very small or very large. Complementary log-log regression model was used in this study because the model is apt for the data set and satisfied the assumptions for the model. The complementary log-log model takes into account the fact that affirmative responses are more likely and gives a better representation. 55\% or more of the responses in this study were affirmative and this satisfies the assumption for the model. The responses for the outcome variable "are you aware that exposure to silica dust can be harmful to your health"? revealed (11\% no, $89 \%$ yes). Covariates such as compositional (age, educational attainment, family status, marital status) and contextual (region of residence) factors were controlled in the models. The effect size of the relationship was determined using the odds ratio (OR). An OR of 1 implies that the explanatory variable does not affect the odds of reporting awareness on the harmful effects of silica dust exposure among stone quarry workers; OR > 1 means that the explanatory variable is associated with higher odds of reporting awareness on the harmful effects of silica dust exposure; OR $<1$ means that the explanatory variable is associated with lower odds of reporting awareness on the harmful 
effects of silica dust exposure. To correct any statistical outliers in the estimation of standard errors (SE), robust estimates of variance were run. Statistical significance was set at 0.05 and the confidence interval at $95 \%$.

\section{Results}

\section{Descriptive statistics}

The percentage distribution of stone quarry workers' awareness of the adverse health effects of silica dust exposure across the study regions is presented in Figure 2. The level of awareness on the adverse health effects of silica dust exposure was lowest (21\%) among workers in the Central region. However, workers in the Ashanti and Eastern regions respectively had the highest (97\%) level of awareness on the adverse health effects of silica dust exposure among the regions. The results show that awareness levels among workers in Greater Accra (91\%) and Western (81\%) regions were also high.

\section{Measures of association}

The Pearson chi-square and Cramer's V results indicating the association between work experience and awareness on adverse health effects of silica dust exposure and the compositional and contextual factors are shown in the contingency table (Table 1). The results rejected the null hypothesis that work experience is independent of the level of awareness on adverse health effects of silica dust exposure, implying that there is a significant relationship between work experience and awareness of the adverse health effects of silica dust exposure. The results show a weak association $(\mathrm{P}=0.003$, Cramer's V $=0.1510)$ between work experience and the level of awareness on adverse health effects of silica dust exposure. According to the results, all the other covariates had a weak association with the measured variable. Based on the Cramer's $\mathrm{V}$ statistics, the strength of association between predictors and the level of awareness on the adverse health effects of silica dust exposure in decreasing order of magnitude, is as follows: region of residence > work experience $>$ educational attainment $>$ marital status $>$ age group $>$ family status.

\section{Multivariate analyses}

Three models were run at the multivariate level, namely, work experience (model 1), work experience and compositional factors (model 2), and contextual factors (model 3) to assess their influence on the level of awareness on adverse health effects of silica dust exposure among stone quarry workers in Ghana. Table 2 
shows the proportional odds ratios, robust standard errors, probability values, and confidence intervals in the models.

In model 1 (Table 2), stone quarry workers who had between 6 to 10 years of work experience in the stone quarry industry were $33 \%(\mathrm{OR}=1.433, \mathrm{P}=0.004)$ more likely to be aware of the adverse health effects of silica dust exposure compared to their counterparts who had between 1 to 5 years work experience in the industry. Individuals who worked for more than 10 years were $59 \%(\mathrm{OR}=1.594, \mathrm{P}=0.007)$ more likely to be aware of the adverse health effects of silica dust exposure compared to those who worked between 1 to 5 years in the sector.

In model 2 (work experience and compositional factors), the direction of the relationship between work experience and the level of awareness on adverse health effects of silica dust exposure among stone quarry workers persisted, the odds ratios increased and the probability values indicate that the relationship was not by chance compared to the results in model 1. Concerning this model (Table 2), I observed that stone quarry workers who had 6 to 10 years of work experience were $79 \%(\mathrm{OR}=1.792, \mathrm{P}=0.000)$ more likely to be aware of the adverse health effects of silica dust exposure compared to their counterparts who had 1 to 5 years work experience in the industry. Individuals who had more than 10 years of work experience in the stone quarry industry were $102 \%(\mathrm{OR}=2.020, \mathrm{P}=0.000)$ far more likely to be aware of the adverse health effects of silica dust exposure compared to their colleagues who had between 1 to 5 years work experience. Middle-aged adults were $49 \%$ ( $O R=0.515, \mathrm{P}=0.000)$ less likely to be aware of the adverse health effects of silica dust exposure compared to the young adult group. Workers who attained secondary or higher education were $30 \%(\mathrm{OR}=1.302, \mathrm{P}=0.040)$ more likely to be aware of the adverse health effects of silica dust exposure compared to their counterparts who had no education.

When contextual factors (model 3) were controlled, the direction of the relationship between work experience and the measured variable remained the same as observed in models 1 and 2 . However, the odds ratios and the level of statistical significance reduced compared to model 2, indicating partial mediation of the relationship. Individuals who had 6 to 10 years of work experience and more than 10 years' work experience in the industry were $48 \%(\mathrm{OR}=1.475, \mathrm{P}=0.021)$ and $82 \%(\mathrm{OR}=1.816, \mathrm{P}=0.003)$ respectively more likely to be aware of the adverse health effects associated with silica dust exposure compared to those who had worked in the industry between 1-5 years.

Just like the results revealed in model 2, the direction of the relationship between age and the predicted variable, educational attainment, and the predicted variable did not change compared to model 2. Nonetheless, compared to model 2, the level of statistical significance between the variables (age and educational attainment) and the predicted variable dropped in this model. The results show that stone quarry 
workers who were middle-aged adults were $38 \%(\mathrm{OR}=0.621, \mathrm{P}=0.0018)$ less likely to be aware of the adverse health effects of silica dust exposure compared with individuals in the young adult category. Workers who had secondary or higher education were $32 \%(\mathrm{OR}=1.320, \mathrm{P}=0.036)$ more likely to be aware of the adverse health effects of silica dust exposure compared to their counterparts who had no education. Regarding geographical location, stone quarry workers in the Ashanti region and the Eastern region were $86 \%(\mathrm{OR}=1.858, \mathrm{P}=0.004)$ and $95 \%(\mathrm{OR}=1.952, \mathrm{P}=0.001)$ respectively more likely to be aware of the adverse health effects of silica dust exposure compared to their counterparts in the Central region. However, family status and marital status were not significant predictors of awareness on the adverse health effects of silica dust exposure among stone quarry workers in all the models.

\section{Ethical Considerations}

This study was conducted according to the ethical standards and guidelines of the Minerals Commission and the Environmental Protection Agency of Ghana. Permission was obtained from managers of the various stone quarries that were visited for the study, the objectives and other details of the study were well explained to the managers before the commencement of data collection. Oral and written consent was obtained from all the participants with a detailed justification of the study procedure and purpose of the study. Participants were not forced or induced financially to take part in the study. It was explained to all the participants that participation in the study was purely voluntary and anyone who wished to withdraw during or after data were collected was allowed to do so. Participants were also made to understand what was required of them and how important the information being sort from them will help improve safety and health considerations in the stone quarry industry.

\section{Discussion}

In this current study, I examined the impact of work experience on the level of awareness on adverse health effects of silica dust exposure among stone quarry workers in Ghana, evaluated how the relationship is attenuated when theoretically relevant compositional and contextual factors were considered, and assessed the order of association between the predictors and the predicted variable. The findings confirmed that work experience has a significant effect on the level of awareness of the adverse health effects of silica dust exposure among stone quarry workers. Individuals who spent six years or more working in the stone quarry industry demonstrated superior understanding and knowledge of the adverse health effects of silica dust exposure than those who have been in the industry for less than six years. This finding implies that as work 
experience increases, awareness of the health hazards among silica-exposed workers increases. The finding is in tandem with what Nguyen et al., (2021) found in their study that examined knowledge, attitude, and practices on silicosis among high-risk workers in Vietnam. Also, Tadesse et al., (2016) found that workers' awareness of occupational health hazards is positively associated with higher work experience, this finding is in line with what I found in this current study.

The relationship between age and the level of awareness on the adverse health effects of silica dust exposure among stone quarry workers revealed some interesting findings. The general expectation is that the older the worker, the better the worker exhibits awareness, understanding, and knowledge on issues of occupational health and safety. Surprisingly, the finding revealed something different. The results show that middle-aged stone quarry workers had a higher likelihood of being unfamiliar with the adverse health effects of silica dust exposure while young adult workers were had a higher chance of being aware of the human health effects. This is at variance with what Sabitu et al (2009) found in their studies where older workers were aware of health hazards issues at the workplace than their younger counterparts. Dragano et al., (2018) and Rohlman et al., (2013) also established contradictory findings. What I found is not in line with the extant literature showing that the relationship is complex and needs further research to unravel the complexities.

The findings demonstrate that higher educated stone quarry workers have a better understanding of the adverse health effects of silica dust exposure than those who had primary or no education. This means that the more educated the stone quarry worker is, the better he or she appreciates the consequences of silica dust exposure. This finding is not surprising because higher educated workers are usually better informed on issues regarding occupational health hazards. Aluko et al., (2016) in their study on knowledge, attitudes, and perceptions of occupational hazards and safety practices in Nigerian healthcare workers found that educational status is positively associated with occupational health knowledge. Based on our findings, we can conclude that higher educated stone quarry workers can read and understand the health hazards associated with silica dust exposure than those with lower education or no education. It has been established that higher educational attainment is significantly associated with worker's health hazard awareness (Nguyen et al., 2021; Tadesse et al., 2016).

The results established a relationship between workers' awareness of the adverse health effects of silica dust exposure and the geographical location of workers. I found that stone quarry workers in the Ashanti and Eastern regions had a higher chance of being aware of the harmful effects of silica dust exposure than their counterparts in the Central region. This could be because stone quarries in these two regions are doing something right. An explanation for this finding may be that the stone quarries in these two regions are regularly providing the needed training and education on the health hazards associated with silica dust 
exposure to their workers. It could also be that workers in these two regions generally have higher educational attainments than their counterparts in the Central region and which makes them have have a better knowledge and understanding what silica dust exposure can negatively do to their health.

\section{Strengths and limitations of the study}

The main strength of the study is the use of empirical data which were collected from people who are directly involved in stone quarry work in Ghana. This enabled us to obtain first-hand information from stone quarry workers (participants). Nonetheless, the use of self-reported survey data to assess the effect of work experience on the level of awareness on harmful effects of silica dust exposure among stone quarry workers was a limitation because there is a likelihood of obtaining bias responses from participants who are disgruntled about conditions unrelated to their safety and health at the workplace. Even though selfreported data collection procedures are known to have some limitations, Siu et al (2003) explained that selfreported measures have been demonstrated to be effective in workplace safety studies. Despite all the limitations of using a self-reported method in collecting the survey data, the findings established a statistically significant relationship between work experience and the level of awareness on harmful effects of silica dust exposure among stone quarry workers in Ghana.

\section{Conclusion}

The findings established a strong relationship between work experience and stone quarry workers' level of awareness of health hazard associated with silica dust exposure. Stone quarry workers who worked in the industry for long years (six years and above) were more likely to be aware of the harmful effects associated with silica dust exposure than those who worked for shorter years (less than six years). We established that workers who attained higher education have a higher chance of being aware of the health hazards associated with silica dust exposure than those who have no or lower educational attainment. Our findings provide important information for stone quarry managers and policymakers to draw strategies relevant for creating the needed awareness about the health hazards associated with silica dust exposure. 


\section{References}

Ahadzi, D. F., Afitiri, A.-R., Ekumah, B., Kanatey, V., \& Afedzi, A. (2020). Self-reported disease symptoms of stone quarry workers exposed to silica dust in Ghana. Health Science Reports, 3(4), e189. https://doi.org/10.1002/hsr2.189

Aluko, O. O., Adebayo, A. E., Adebisi, T. F., Ewegbemi, M. K., Abidoye, A. T., \& Popoola, B. F. (2016). Knowledge, attitudes and perceptions of occupational hazards and safety practices in Nigerian healthcare workers. BMC Research Notes, 9(1), 71. https://doi.org/10.1186/s13104-016-1880-2

Attfield, M. D., \& Costello, J. (2004). Quantitative exposure-response for silica dust and lung cancer in Vermont granite workers. American Journal of Industrial Medicine, 45(2), 129-138. https://doi.org/10.1002/ajim.10348

Castranova V, \& Vallyathan V. (2000). Silicosis and coal workers' pneumoconiosis. Environmental Health Perspectives, 108(suppl 4), 675-684. https://doi.org/10.1289/ehp.00108s4675

Collins, J., Ward, B. M., Snow, P., Kippen, S., \& Judd, F. (2017). Compositional, Contextual, and Collective Community Factors in Mental Health and Well-Being in Australian Rural Communities. Qualitative Health Research, 27(5), 677-687. https://doi.org/10.1177/1049732315625195

Dahmann, D., Taeger, D., Kappler, M., Büchte, S., Morfeld, P., Brüning, T., \& Pesch, B. (2008). Assessment of exposure in epidemiological studies: The example of silica dust. Journal of Exposure Science \& Environmental Epidemiology, 18(5), 452-461. https://doi.org/10.1038/sj.jes.7500636

Ding, M., Chen, F., Shi, X., Yucesoy, B., Mossman, B., \& Vallyathan, V. (2002). Diseases caused by silica: Mechanisms of injury and disease development. International Immunopharmacology, 2(2), 173-182. https://doi.org/10.1016/S1567-5769(01)00170-9

Dragano, N., Barbaranelli, C., Reuter, M., Wahrendorf, M., Wright, B., Ronchetti, M., Buresti, G., Di Tecco, C., \& Iavicoli, S. (2018). Young Workers' Access to and Awareness of Occupational Safety and Health Services: Age-Differences and Possible Drivers in a Large Survey of Employees in Italy. International Journal of Environmental Research and Public Health, 15(7). https://doi.org/10.3390/ijerph15071511

Falk, L., Bozek, P., Ceolin, L., Levitsky, M., Malik, O., Patel, J., Sobers, M., \& Cole, D. C. (2019). Reducing agate dust exposure in Khambhat, India: Protective practices, barriers, and opportunities. Journal of Occupational Health, 61(6), 442-452. https://doi.org/10.1002/13489585.12067 
Gottesfeld, P., Tirima, S., Anka, S. M., Fotso, A., \& Nota, M. M. (2019). Reducing Lead and Silica Dust Exposures in Small-Scale Mining in Northern Nigeria. Annals of Work Exposures and Health, 63(1), 1-8. https://doi.org/10.1093/annweh/wxy095

Hasanzadeh, S., Esmaeili, B., \& Dodd, M. D. (2017). Measuring the Impacts of Safety Knowledge on Construction Workers' Attentional Allocation and Hazard Detection Using Remote Eye-Tracking Technology. Journal of Management in Engineering, 33(5), 04017024. https://doi.org/10.1061/(ASCE)ME.1943-5479.0000526

Kabir, E., Islam, A., \& Taufikuzzaman, Md. (2018). An investigation into respiratory health problems of workers at stone crushing industries in Bangladesh. Journal of Health Research, 32(2), 172-178. https://doi.org/10.1108/JHR-01-2018-017

Kamkuimo, S. A. K., Girard, B., Lapointe, P., \& Menelas, B.-A. J. (2020). Design and Implementation of a Serious Game to Make Construction Workers Aware of Exposure to Silica Dust in the Workplace. In M. Ma, B. Fletcher, S. Göbel, J. Baalsrud Hauge, \& T. Marsh (Eds.), Serious Games (pp. 85-98). Springer International Publishing. https://doi.org/10.1007/978-3-030-61814$8 \_7$

Lugah, V., Ganesh, B., Darus, A., Retneswari, M., Rosnawati, M. R., \& Sujatha, D. (2010). Training of occupational safety and health: Knowledge among healthcare professionals in Malaysia. Singapore Medical Journal, 51(7), 586-592.

Maciejewska, A. (2008). Occupational Exposure Assessment for Crystalline Silica Dust: Approach in Poland and Worldwide. International Journal of Occupational Medicine and Environmental Health, 21(1), 1-23. https://doi.org/10.2478/v10001-008-0010-3

Momani, A., Hirzallah, M., \& Mumani, A. (2017). Improving Employees' Safety Awareness in Healthcare Organizations Using the DMAIC Quality Improvement Approach. The Journal for Healthcare Quality (JHQ), 39(1), 54-63. https://doi.org/10.1097/JHQ.0000000000000049

Nandi, S., Burnase, N., Barapatre, A., Gulhane, P., \& Dhatrak, S. (2018). Assessment of Silicosis Awareness among Stone Mine Workers of Rajasthan State. Indian Journal of Occupational and Environmental Medicine, 22(2), 97-100. https://doi.org/10.4103/ijoem.IJOEM_63_18

Nguyen, V., Thu, H. N. T., Le Thi, H., Ngoc, A. N., Van, D. K., Thi, Q. P., Nhu, N. T., Thanh, T. N., Quoc, D. N., Mai, H. P. T., Kim, N. T. T., Mai, A. L., Lien, H. N. T., \& Le Thi Thanh, X. (2021). Knowledge, Attitude, and Practices (KAP) on Silicosis Among High-Risk Worker Population in Five Provinces in Vietnam. In X.-N. Bui, C. Lee, \& C. Drebenstedt (Eds.), Proceedings of the International Conference on Innovations for Sustainable and Responsible Mining (pp. 469-484). Springer International Publishing. https://doi.org/10.1007/978-3-030-60839-2_25 
Pol, L. G., \& Thomas, R. K. (2013). Population Size, Distribution and Concentration. In L. G. Pol \& R. K. Thomas (Eds.), The Demography of Health and Healthcare: Third Edition (pp. 37-63). Springer Netherlands. https://doi.org/10.1007/978-90-481-8903-8_3

Rees, D., Murray, J., Nelson, G., \& Sonnenberg, P. (2009). Oscillating migration and the epidemics of silicosis, tuberculosis, and HIV infection in South African gold miners. American Journal of Industrial Medicine, 53(4), 398-404. https://doi.org/10.1002/ajim.20716

Rice, F. L., Park, R., Stayner, L., Smith, R., Gilbert, S., \& Checkoway, H. (2001). Crystalline silica exposure and lung cancer mortality in diatomaceous earth industry workers: A quantitative risk assessment. Occupational and Environmental Medicine, 58(1), 38-45. https://doi.org/10.1136/oem.58.1.38

Riley, W. T. (2012). Leveraging Technology for Multiple Risk Factor Interventions: Comment on "Multiple Behavior Changes in Diet and Activity." Archives of Internal Medicine, 172(10), 796798. https://doi.org/10.1001/archinternmed.2012.1633

Rohlman, D. S., Parish, M., Elliot, D. L., Montgomery, D., \& Hanson, G. (2013). Characterizing the Needs of a Young Working Population: Making the Case for Total Worker Health in an Emerging Workforce. Journal of Occupational and Environmental Medicine, 55, S69. https://doi.org/10.1097/JOM.0000000000000039

Ross, C. E., \& Mirowsky, J. (2008). Neighborhood Socioeconomic Status and Health: Context or Composition? City \& Community, 7(2), 163-179. https://doi.org/10.1111/j.15406040.2008.00251.x

Sabitu, K., Iliyasu, Z., \& Dauda, M. M. (2009). Awareness of occupational hazards and utilization of safety measures among welders in kaduna metropolis, Northern Nigeria. Annals of African Medicine, 8(1), 46. https://doi.org/10.4103/1596-3519.55764

Sayler, S. K., Long, R. N., Nambunmee, K., \& Neitzel, R. L. (2018). Respirable silica and noise exposures among stone processing workers in northern Thailand. Journal of Occupational and Environmental Hygiene, 15(2), 117-124. https://doi.org/10.1080/15459624.2017.1393080

Seaton, A., Legge, J. S., Henderson, J., \& Kerr, K. M. (1991). Accelerated silicosis in Scottish stonemasons. The Lancet, 337(8737), 341-344. https://doi.org/10.1016/0140-6736(91)90956-P

Sharma, N., Kundu, D., Dhaked, S., \& Das, A. (2016). Silicosis and silicotuberculosis in India. Bulletin of the World Health Organization, 94(10), 777-778. https://doi.org/10.2471/BLT.15.163550

Siu, O., Phillips, D. R., \& Leung, T. (2003). Age differences in safety attitudes and safety performance in Hong Kong construction workers. Journal of Safety Research, 34(2), 199-205. https://doi.org/10.1016/S0022-4375(02)00072-5 
Sivanmani, K., \& Rajathinakar, V. (2013). Silicosis in Coimbatore district of Tamil Nadu: A passive surveillance study. Indian Journal of Occupational and Environmental Medicine, 17(1), 25-28. https://doi.org/10.4103/0019-5278.116370

Tadesse, S., Bezabih, K., Destaw, B., \& Assefa, Y. (2016). Awareness of occupational hazards and associated factors among welders in Lideta Sub-City, Addis Ababa, Ethiopia. Journal of Occupational Medicine and Toxicology, 11(1), 15. https://doi.org/10.1186/s12995-016-0105-x

Tam, V. W. Y., \& Fung, I. W. H. (2008). A Study of Knowledge, Awareness, Practice and Recommendations Among Hong Kong Construction Workers on Using Personal Respiratory Protective Equipment at Risk. The Open Construction and Building Technology Journal, 2(1). https://benthamopen.com/ABSTRACT/TOBCTJ-2-69

Yassin Abdiaziz, Yebesi Francis, \& Tingle Rex. (2005). Occupational Exposure to Crystalline Silica Dust in the United States, 1988-2003. Environmental Health Perspectives, 113(3), 255-260. https://doi.org/10.1289/ehp.7384 
Table 1. Percentage distribution of awareness on the harmful effects of silica dust exposure by predictor variables.

\begin{tabular}{|c|c|c|c|}
\hline \multirow[t]{2}{*}{ Variable } & \multicolumn{2}{|c|}{$\begin{array}{l}\text { Awareness of adverse } \\
\text { health effects of silica } \\
\text { dust exposure }\end{array}$} & \multirow[t]{2}{*}{ Inferential statistics } \\
\hline & No $(\%)$ & Yes $(\%)$ & \\
\hline \multicolumn{4}{|l|}{ Work experience } \\
\hline $\begin{array}{l}1-5 \text { years } \\
6-10 \text { years } \\
\text { Above } 10 \text { years }\end{array}$ & $\begin{array}{l}16.20 \\
7.37 \\
5.49\end{array}$ & $\begin{array}{l}83.80 \\
92.63 \\
94.51\end{array}$ & $\begin{array}{l}\chi 2=11.9542 \\
(\mathrm{P}-\text { value }=0.003 ; \text { Cramer's V = 0.1510) }\end{array}$ \\
\hline \multicolumn{4}{|l|}{ Age group } \\
\hline $\begin{array}{l}\text { Young adult } \\
\text { Middle-aged adult }\end{array}$ & $\begin{array}{l}8.47 \\
11.82\end{array}$ & $\begin{array}{l}91.53 \\
88.18\end{array}$ & $\begin{array}{l}\chi 2=1.3707 \\
(\mathrm{P}-\text { value }=0.242 ; \text { Cramer's } \mathrm{V}=-0.0511)\end{array}$ \\
\hline \multicolumn{4}{|l|}{$\begin{array}{l}\text { Educational } \\
\text { attainment }\end{array}$} \\
\hline $\begin{array}{l}\text { Primary/ No education } \\
\text { Secondary or higher }\end{array}$ & $\begin{array}{l}12.58 \\
8.11\end{array}$ & $\begin{array}{l}87.42 \\
91.89\end{array}$ & $\begin{array}{l}\chi 2=2.6840 \\
(\mathrm{P} \text {-value }=0.101 ; \text { Cramer's V }=0.0716)\end{array}$ \\
\hline \multicolumn{4}{|l|}{ Family status } \\
\hline $\begin{array}{l}\text { Head } \\
\text { Member }\end{array}$ & $\begin{array}{l}9.80 \\
13.79\end{array}$ & $\begin{array}{l}90.20 \\
86.21\end{array}$ & $\begin{array}{l}\chi^{2}=1.5059 \\
(P \text {-value }=0.220 ; \text { Cramer's V }=-0.0536)\end{array}$ \\
\hline \multicolumn{4}{|l|}{ Marital status } \\
\hline $\begin{array}{l}\text { Single } \\
\text { Married } \\
\text { Divorced }\end{array}$ & $\begin{array}{l}12.28 \\
10.39 \\
8.00\end{array}$ & $\begin{array}{l}87.72 \\
89.61 \\
92.00\end{array}$ & $\begin{array}{l}\chi 2=0.5281 \\
(\mathrm{P}-\text { value }=0.768 ; \text { Cramer's V }=0.0317)\end{array}$ \\
\hline \multicolumn{4}{|l|}{ Region } \\
\hline $\begin{array}{l}\text { Central } \\
\text { Western } \\
\text { Greater Accra } \\
\text { Ashanti } \\
\text { Eastern }\end{array}$ & $\begin{array}{l}21.00 \\
18.81 \\
8.85 \\
2.97 \\
2.75\end{array}$ & $\begin{array}{l}79.00 \\
81.19 \\
91.15 \\
97.03 \\
97.25\end{array}$ & $\begin{array}{l}\chi 2=32.0188 \\
(\mathrm{P} \text {-value }=0.000 ; \text { Cramer's V }=0.2472)\end{array}$ \\
\hline
\end{tabular}


Table 2. Complementary log-log regression model showing the relationship between the level of awareness on the adverse health effects of silica dust exposure among stone quarry workers and predictor variables $(n=524)$

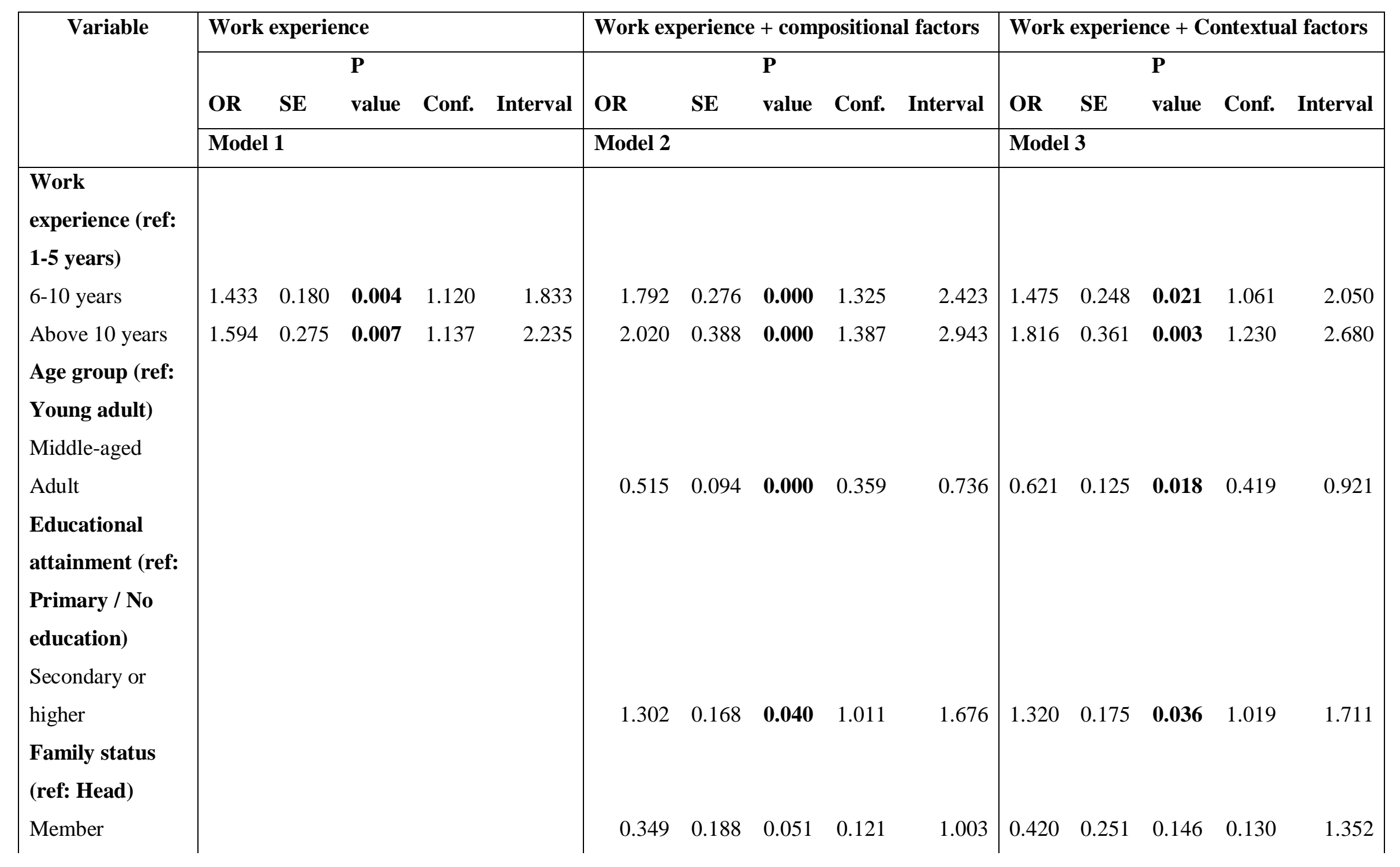




\begin{tabular}{|c|c|c|c|c|c|c|c|c|c|c|}
\hline \multicolumn{11}{|l|}{$\begin{array}{l}\text { Marital status } \\
\text { (ref: Single) }\end{array}$} \\
\hline Married & 0.508 & 0.281 & 0.221 & 0.171 & 1.504 & 0.537 & 0.329 & 0.310 & 0.161 & 1.784 \\
\hline Divorced & 0.601 & 0.368 & 0.406 & 0.181 & 1.996 & 0.675 & 0.450 & 0.556 & 0.183 & 2.495 \\
\hline \multicolumn{11}{|l|}{ Region (ref: } \\
\hline \multicolumn{11}{|l|}{ Central) } \\
\hline Western & & & & & & 0.978 & 0.177 & 0.904 & 0.686 & 1.395 \\
\hline Greater Accra & & & & & & 1.281 & 0.241 & 0.187 & 0.887 & 1.851 \\
\hline Ashanti & & & & & & 1.858 & 0.396 & 0.004 & 1.224 & 2.821 \\
\hline Eastern & & & & & & 1.952 & 0.394 & 0.001 & 1.315 & 2.900 \\
\hline
\end{tabular}




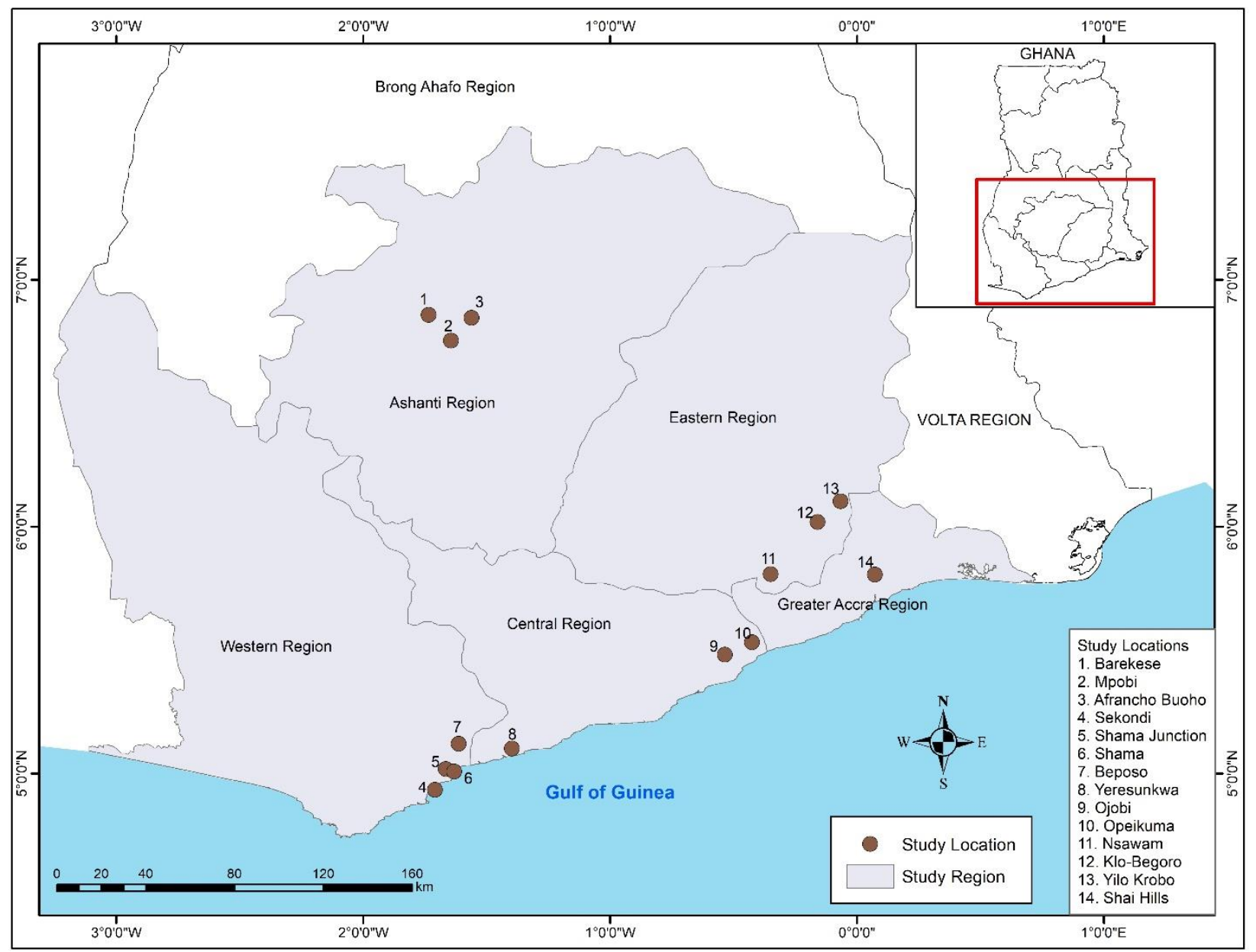

Fig. 1. A map showing the communities where the stone quarries are located in the five study regions (Source: Ahadzi et al., 2020) 


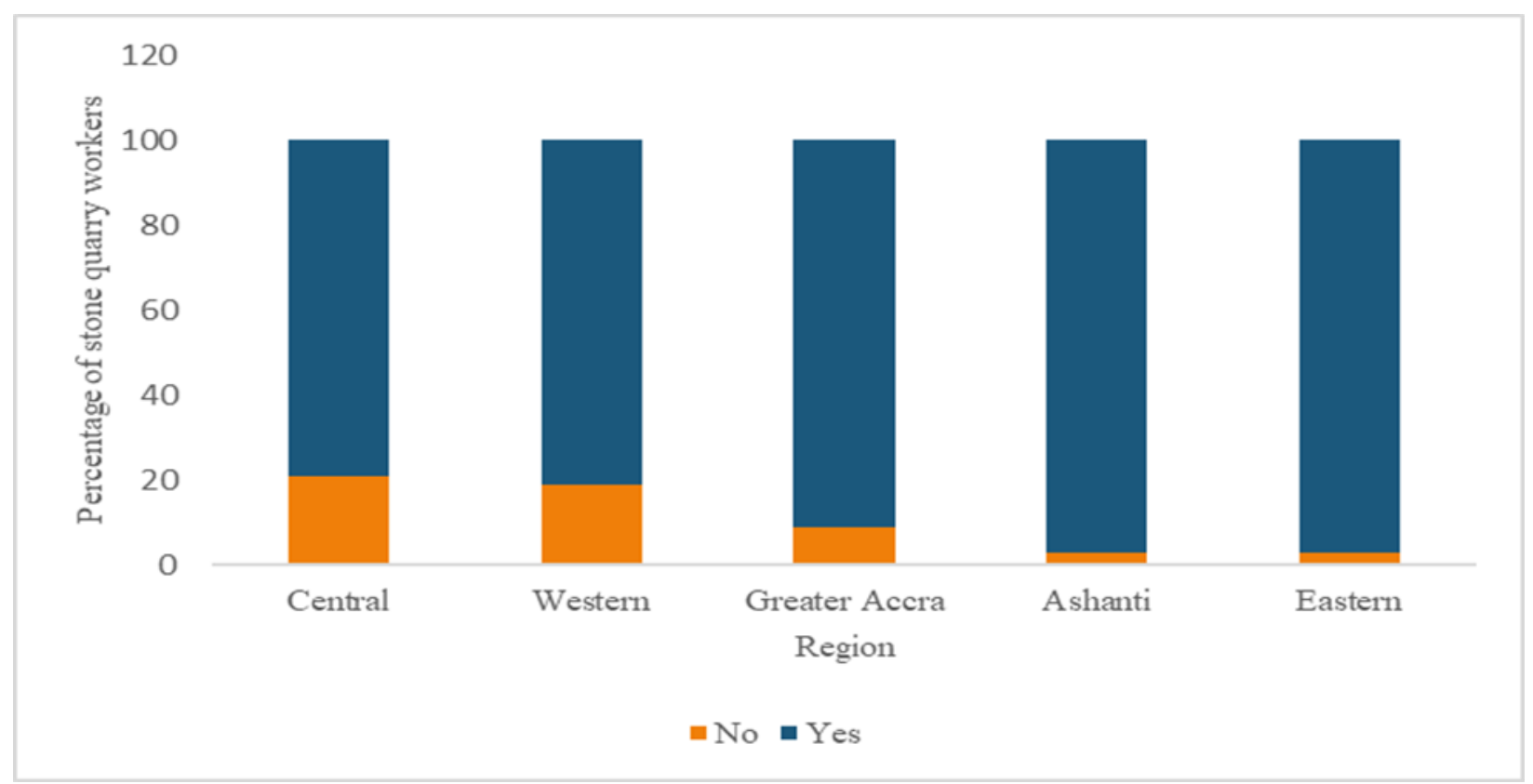

Fig. 2. Awareness of adverse health effects associated with silica dust exposure among stone quarry workers across the study regions 